Calculation of Monte Carlo Importance

Functions for Use in Nuclear-Well Logging Calculations *

P.D. Soran, Lawrence Livermore National Laboratory

D.C. McKeon, Schlumberger Well Services

T.E. Booth, Los Alamos National Laboratory

UCRL -201563

DE89 016507

Importance sampling is essential to the timely solution of Monte Carlo nuclear-logging computer simulations.

Achieving minimum variance (maximum precision) of a response in minimum computation time is one criteria for the choice of an importance function. Various methods for calculating importance functions will be presented, new methods investigated, and comparisons with porosity and density tools will be shown.

*Work performed under the auspices of the U.S. Dept. of Energy by the Lawrence Livermore National

Laboratory under Contract No. W-7405-ENG-48.

Contact:

Patrick D. Soran

Lawrence Livermore National Laboratory

PO Box 808, L-16

Livermore, CA 94550

(415)-423-4633 


\section{DISCLAIMER}

This report was preparod as an account of work sponsored by an ageacy of the United States Goverament Neither the United States Government not any agency thereor, nor any of their employees, makes any warranty, express or implied, or assumes any legal liability or responsibility for the accuracy, completeness, of usefulness of any information, apparatus, product, or prooess disalused. or represents that its use would not infriage privalely owned righs. Reference herein to any specific commercial product, process, ar service by trade name, trademark, manufacturer, of otherwise doss not nocessarily constitute or imply its endorsement, recommendation, or favoriag by the United States Government at any agency thereos. The views and opinions of authors expressed herein do not otessarily statc or reflect those of the United States Government or any agency thereof. 


\title{
Calculation of Monte Carlo Importance \\ Functions for Use in Nuclear-Well Logging Calculations
}

\author{
P.D. Soran, Lawrence Livermore National Laboratory; \\ D.C. McKeon, Schlumberger Well Services; \\ T.E. Booth, Los Alamos National Laboratory
}

\section{Introduction}

Variance-reduction or biasing techniques are required in Monte Carlo calculations to reduce the computational time, required to obtain resuits of sufficient piecision. There are many Monte Carlo biasing techniques that require approximate importance information. Similarly, there are a number of Monte Carlo techniques that can be used to provide importance/bjasing information. Monte Carlo importance generators often produce poor estimates in regions of poor sampling or in regions of low importance. Two newly developed techniques, a quasi-deterministic ${ }^{1}$ and an integral transport ${ }^{2}$ solution, are investigated as alternatives to stochastically generated importasce functions.

\section{Liscussion}

The efficiency of a Monte Carlo calculation is affected by the type of tally and the random walk sampling. The tally choice tries to obtain the best results from the random walks sampled. Random walk sampling amounts to preferentially sampling important random walks at the expense of unimportant random walks. Analog Monte Carlo simply samples events according to their natural physical probabilities. Analog calculations estimate the number of physical particles executing any given random walk. Nonanalog techniques do not directly simulate natural physical probabilities. Nonanalog techniques are free to do anything as long as the particle density is preserved. Preservation is accomplished by adjusting the weight of the particles. There are three basic types of nonanalog games: (1) splitting, (2) Russian roulette, and (3) sampling from noranalog probability density functions.

Successful use of variance reduction techniques is often more art than science. After the techniques are selected, the user has to supply parameters. Parameter choices are important since the user is trying to minimize the product of the variance and the compiter time usinge. Parameters are chosen based on experience from similar problems, guessing. ur generation. One widely used method is the importance generator ${ }^{3}$. Although this generator has teen successful in many logging problenss, it is a staristical method that can produce poor or no estimates in regions of poor sarnpling or low importance. Failure results when very few particles enter a region, and when even tewer of the entering particles subsequently score.

The quasi-deterministic method antacks these deficiencies by sourcing particles into all regions and only requiring a particle undergo one step in the transport process 
betore making an estimate of the particle's average score. The integral transport method calculates the multigroup adjoint fluxes based on a diffusion approximation to the integral transport method. Both methods provide a deterministic calculation of importance functions in complex geometries. The value of these techniques is that some of the "art" is removed from variance reduction and ine user interface is significantly simplified.

Using the neutron benchmark porosity tool proposed by Gardner ${ }^{4}$, several calculations were performed for a 20 porosity unit limestone formation using the MCNP cude. (Similiar calculations have been performed for a gamma-ray density tool.) Table $I$ illustrates the calculational efficiency, on a Cray X/MP for both the near and the tar detector.

Table 1

FOM for Various Variance Reduction Techniques

(FOM=1/[relative error ${ }^{2}$ "cpu time])

$\begin{array}{clll}\text { Case } & \text { Model } & \text { FOM } & \text { Description } \\ 1 & \text { Implicit } & 0.2 & \text { All importances 1 } \\ 2 & \text { Wgt Window } & 0.9 & \text { Starting with unity importances } \\ 3 & \text { Int. Trans } & 10 & 1431 \text { cells, } 9 \text { neutron. groups } \\ 4 & \text { Wgt Window } & 18 & \text { Initialize with Case 3 parameters (two separate runs) } \\ 5 & \text { Wgt Window } & 12 & \text { Initialize with Case 3 parameters both detectors } \\ 6 & \text { Quasi-deter } & 9 & \text { Optimize for near detector }\end{array}$

The problem is ditficult because: there is considerable neutron thermalization; the near and far detectors are $30 \mathrm{~cm}$ apart; and a low variance response is sought at each detector. Optimization of the near detector response causes the far detector response to suffer and vice versa. Cases 2,4 , and 5 require considerable user intervention, whereas 3 and 6 do not. Case 1 places all spatial cells in the problem at unity, which is a reasonable starting point for generation. Next, weight windows are generated starting with all cells having importance of 1 . In most cases, a user would "hootstrap" case 2 to a level where the FOM was reasonable. Case 4 illustrates optimizing the near and far detector, making two (2) calculations, and combining the results. Finally, case 5 is an attempt at a near/tir optimization by forcing a percentage of the neutrons to both the near and far detector during the generation stage.

\section{Conclusion}

The quasi-deterministic and integral transport methods have advantages over current stochastic methods. With both methods there is no problem getting particles into every region beciluse they are either sourced in or determined from an adjoint solution. Each method provides importance estimates which yield calculational efficiency greater than stochastic methods. Also, the user is relieved of having to choose initial biassing and of adjusting the function in the poor statistics regions for stochassic generators. 


\section{References}

1. Thomas E. Bowth, "A Quasi-Deterministic Approximation of the Monte Carlo Importante Function.Trans. Am. Nucl. Soc., 1987, 55, pp .358-9.

3. D.C. McKeon. "A New Integral Transport Solution to the Neutron Transport Equation in Complex. Three-Dimensional Geometries," PhD Dissertation, University of New Mexico (1985).

3. Thomas E. B(x)th and John S. Hendricks, "Importance Estimation in Forward Monte Carlo Calculations," Nuc. Tech/Fusion, Vol. 5. January 1984.

4. R.C. Little. M. Mickacl, K Verghesc, and R.P. Gardner, "Benchmark Neutron Porosity Log Calculations: A Comparison of MCNP und the Specific Purpose Code McDNL" presented at the IEEE 1988 Nuckear Science Symposium . Orlando, Florida (Oct 1988).

5. J.F. Briesmcister, Ed.,"MCNP-A Gencral Monte Carlo Code for Neutron and Photon Transport (Version 5A)," Los Alimis National Luboratory report LA-7396-M, Rev. 2 (Sept 1986). 